\title{
Editorials
}

\section{New approaches to dealing with opioid drug dependence}

In England there are an estimated 260000 heroin users. ${ }^{1}$ Globally, 210 million people use illicit drugs each year, leading to approximately 200000 deaths. ${ }^{2}$ Last year the UK government launched a new drug strategy that claimed to offer a fundamentally different approach to dealing with drug dependence, placing the concept of 'recovery' at its heart. ${ }^{3}$ But what is recovery and is it really a new approach to patient care? Also, how may this affect primary care clinicians day-to-day management of patients with drug problems?

\section{FOCUS ON RECOVERY}

The subtitle to the new drug strategy makes the aim clear: 'Supporting people to live a drug-free life'. This represents a shift from a harm-reduction approach, where needle exchange programmes and opioid substitution treatment have been seen as key interventions. The new strategy emphasises the importance of going further with the expectation that full recovery is possible and desirable. ${ }^{3}$

While this may seem a logical step, there is a danger that the drive to attain and maintain a drug-free life ignores the hierarchy of goals of drug treatment (Box 1), ${ }^{4}$ where significant benefits, for both individuals and society, can be achieved short of abstinence. The wider recovery movement recognises this and avoids being prescriptive in advocating an abstinencebased approach. The language of the new drug strategy, while not mentioning compulsion directly, suggests an obligation to consider alternative methods: 'for too many people currently on a substitute prescription, what should be the first step on the journey to recovery risks ending there. This must change. ${ }^{3}$ GPs may find that they are encouraged to review patients more frequently with a view to ensuring that individuals are firmly linked in to recoveryfocused activities.

\section{DEFINING RECOVERY}

Over the last 20 years a recovery model within mental health literature, policy, and practice has developed. This was a response to professional and societal attitudes that had previously viewed mental illness as a chronic unremitting disorder. ${ }^{5}$ De-institutionalisation and the mental health service users' voice also helped promote the idea that recovery should be about achieving a socially inclusive, purposeful life, even in the face of limitations due to one's illness. ${ }^{5}$ However, within the mental health field too, there is debate about what recovery means.

In 2005 the National Institute for Mental Health in England offered a broad definition of recovery as, what people experience themselves as they become empowered to manage their lives. ${ }^{6}$ Comparing recovery models for drug dependence with those for mental health, we can note many parallels: an emphasis on wellbeing rather than 'cure'; hope as a central concept; services re-orientated to support people to develop as citizens contributing to society; and allowing individuals choice and control. Emphasising the concept of wellbeing rather than 'cure' in the treatment of drug dependence is crucial to avoid the new centrally-driven recovery agenda being taken to mean that services should only look to support a drug-free status.

\section{TREATMENT AND SUPPORT}

GPs have been encouraged to play an increasing role in the treatment of drug dependence since the mid-1980s. ${ }^{7}$ Primary care treatment arguably offers the advantages of both continuity and integration of drug and non-drug related medical care. GPs are also well used to managing problems at the interface of health and social care. Shared care substance misuse clinics in the UK have allowed primary care doctors to feel more confident in treating such patients, with onsite support of drugs workers and access to specialist drug services when required.

Interventions available to drug users in the primary care setting are either pharmacological or psychosocial. For the foreseeable future the mainstay of pharmacological treatments for opioid dependence will be methadone or buprenorphine, offered as either a maintenance or detoxification regime, according to individual patient need. It is recommended that GPs have been trained to achieve the appropriate competencies to treat drug users ${ }^{8}$ and will usually prescribe as part of a shared care scheme.

Psychosocial interventions include talking therapies aimed at enhancing motivation to change behaviour or cognitive behavioural therapies to treat those with concurrent depressive illnesses. Mindfulness-based cognitive therapy may also be useful for those at risk of relapse from depression.

In 2007 the National Institute for Health and Clinical Excellence recommended contingency management; for example, where incentives such as vouchers or privileges are offered to those on methadone maintenance treatment contingent on drug-negative tests. However, in the new GP-led commissioning landscape and with tight budgets, it is unclear to what extent such approaches will be prioritised.

Other supporting interventions are socalled 'wrap around' services such as housing, employment, and training opportunities; benefits and debt management advice; and parenting support. Variability in the provision of these services may be a factor in the gap between results seen in trials and those in day-today practice.

Newer pharmacological treatments include an extended release injectable form of the opioid antagonist naltrexone to encourage continuing abstinence in former opiate users..$^{10}$ However, it is not currently licensed in the UK and concerns have been raised about limited efficacy and safety data. Buprenorphine is being developed and trialled both as a sub-dermal implant ${ }^{11}$ and as an injectable depot formulation, ${ }^{12}$ that may help with issues of adherence and diversion. Providing families of illicit opiate users with the opioid antagonist naloxone,

\section{Box 1. Hierarchy of goals during drug treatment. ${ }^{4}$}

- Abstinence from all drugs

- Abstinence from main problem drugs

- Attainment of controlled, non-dependent or non-problematic drug use

- Reduction of health, social, or other problems not directly attributable to drug misuse

- Reduction of harmful or risky behaviours associated with the misuse of drugs lfor example, sharing injecting equipment)

- Reduction of health, social, and other problems directly related to drug misuse 


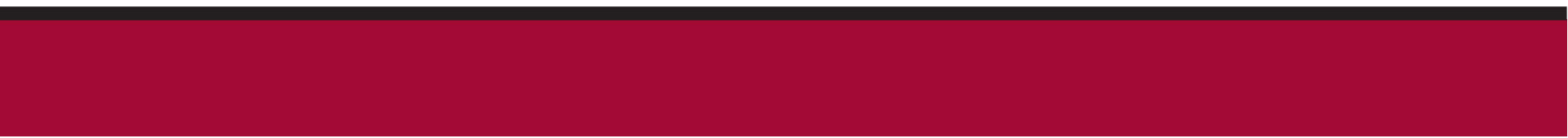

"Providing families of illicit opiate users with the opioid antagonist naloxone to use if patients overdose at home has recently been piloted with some promising results."

to use if patients overdose at home has recently been piloted with some promising results. ${ }^{13}$

Looking further ahead, personalised drug treatment based on a detailed analysis of patients' behavioural traits and better understanding of molecular mechanisms in addiction may offer a way forward. ${ }^{14}$

\section{DEVELOPING SERVICES TOGETHER}

It is in the interests of patients, practitioners, policy leads, and commissioners for primary care to develop further the provision of quality evidencebased treatments for drug users. There is much that all parties can learn from the evolution of recovery models in the mental health field. An emphasis on wellbeing, together with a re-orientation of services to allow greater individual patient choice and control over the management of their illness, are key aspects of care that all stakeholders can hopefully agree are important. A narrow interpretation of the recovery agenda that emphasises the 'cure' of the drug user should be avoided if patients are to be fully supported in finding hope and a greater sense of self-worth in what can be a chronic condition for many.

\section{Bruno J Rushforth}

Clinical Research Fellow in Primary Care, Academic Unit of Primary Care, Leeds Institute of Health

Sciences, University of Leeds.

\section{Nat MJ Wright}

Clinical Director of Substance Misuse, Leeds Cluster of Prisons, Leeds.

\section{Provenance}

Commissioned; externally peer reviewed.

DOI: 10.3399/bjgp11X612927

\section{ADDRESS FOR CORRESPONDENCE}

Bruno Rushforth

Academic Unit of Primary Care, Leeds Institute of

Health Sciences, University of Leeds, Charles

Thackrah Building, 101 Clarendon Road, Leeds, LS2 9LJ, UK.

E-mail: b.j.rushforthdleeds.ac.uk

\section{REFERENCES}

1. NHS National Treatment Agency for Substance Misuse (NTA). Prevalence data.

http://www.nta.nhs.uk/facts-prevalence.aspx laccessed 26 Oct 2011).

2. United Nations Office on Drugs and Crime. World drug report 2011. New York: UNODC, 2011.

3. Home Office. Drug strategy 2010. Reducing demand, restricting supply, building recovery: supporting people to live a drug free life. London: HM Government, 2010.

4. Gerada C. Drug and alcohol problems. Royal College of General Practitioners curriculum statement 15.3. London: Royal College of General Practitioners, 2007.

5. Ramon S, Healy B, Renouf N. Recovery from mental illness as an emergent concept and practice in Australia and the UK. Int J Soc Psychiatry 2007; 53(2): 108-122.

6. National Institute for Mental Health in England. Guiding statement on recovery. London: Department of Health, 2005

7. Gossop M, Marsden J, Stewart D, et al. Methadone treatment practices and outcome for opiate addicts treated in drug clinics and in general practice: results from the National Treatment Outcome Research Study. Br J Gen Pract 1999; 49(438): 31-34.

8. Department of Health (England) and the devolved administrations. Drug misuse and dependence: UK guidelines on clinical management. London: Department of Health (England), the Scottish Government, Welsh Assembly Government and Northern Ireland Executive, 2007

9. National Institute for Health and Clinical Excellence. Drug misuse: psychosocial interventions. Clincial guidelines CG51. London: NICE, 2007

10. Krupitsky E, Nunes EV, Ling W, et al. Injectable extended-release naltrexone for opioid dependence: a double-blind, placebo-controlled, multicentre randomized trial. Lancet 2011; 377(776): 1506-1513.

11. Ling W, Casdonte P, Bigelow G, et al. Buprenorphine implants for treatment of opioid dependence: a randomized controlled trial. JAMA 2010; 304(14): 1576-1583.

12. Sigmon SC, Moody DE, Nuwayser ES, Bigelow GE. An injection depot formulation of buprenorphine: extended bio-delivery and effects. Addiction 2006; 101(3): 420-432.

13. NHS National Treatment Agency for Substance Misuse. The NTA overdose and naloxone training programme for families and carers. London: NTA, 2011.

14. Nutt D. Addiction - where does it start? [presentation]. Royal College of General Practitioners Substance Misuse Management in General Practice conference. Harrogate, 12-13 May 2011.

http://www.smmgp.org.uk/html/rcgpconference/ rep016.php (accessed 26 Oct 2011). 